\title{
Hypoxia down-regulates expression of secretory leukocyte protease inhibitor in bronchial epithelial cells via TGF- $\beta 1$
}

Lisa I Påhlman ${ }^{*}$, Annika Jögi ${ }^{2}$, Magnus Gram ${ }^{1}$ Michiko Mori ${ }^{3}$ and Arne Egesten ${ }^{4}$

\begin{abstract}
Background: Secretory leukocyte protease inhibitor (SLPI) is a protein with anti-protease and antimicrobial properties that is constitutively secreted from the airway epithelium. The importance of maintaining a balance between proteases and anti-proteases, and robust innate defence mechanisms in the airways, is exemplified by inflammatory lung conditions such as chronic obstructive pulmonary disease (COPD) and cystic fibrosis (CF). Both conditions present with a high protease burden in the airways which leads to tissue destruction. These patients also have an impaired innate immune system in the lungs with bacterial colonization and frequent airway infections. Moreover, both diseases are associated with airway hypoxia due to inflammation and mucus plugs. The aim of the present study was to investigate the role of hypoxia on SLPI production from the airway epithelium.
\end{abstract}

Methods: Primary human bronchial epithelial cells were grown in sub-immersed cultures or as differentiated epithelium in air liquid interface cultures. Cells were incubated at 21\% $\mathrm{O}_{2}$ (normoxia) or $1 \% \mathrm{O}_{2}$ (hypoxia), and the release of SLPI was analysed with ELISA. RT-PCR was used to study the expression of SLPI and transforming growth factor $\beta 1$ (TGF- $\beta 1$ ).

Results: Hypoxia decreased the constitutive production of SLPI by bronchial epithelial cells. The multifunctional cytokine TGF- $\beta 1$, which is known to affect SLPI expression, showed increased expression in hypoxic bronchial epithelial cells. When bronchial epithelial cells were exposed to exogenous TGF- $\beta 1$ during normoxia, the SLPI production was down-regulated. Addition of TGF- $\beta 1$-neutralizing antibodies partially restored SLPI production during hypoxia, showing that TGF- $\beta 1$ is an important regulator of SLPI during hypoxic conditions.

Conclusions: The mechanism described here adds to our knowledge of the pathogenesis of severe pulmonary diseases associated with hypoxia, e.g. COPD and CF. The hypoxic down-regulation of SLPI may help explain the protease/anti-protease imbalance associated with these conditions and vulnerability to airway infections. Furthermore, it provides an interesting target for the treatment and prevention of exacerbation in these patients.

Keywords: SLPI, Hypoxia, Airways, Pathogenesis, COPD, CF

\section{Background}

Secretory leukocyte protease inhibitor (SLPI) is a small protein of $11.7 \mathrm{kDa}$ that is secreted by mucosal linings, including the airway epithelium [1]. As the name implies, SLPI has anti-protease activity and plays an important role in neutralizing enzymes such as neutrophil elastase in order to prevent excessive tissue damage during inflammation

\footnotetext{
* Correspondence: lisa.pahlman@med.lu.se

'Department of Clinical Sciences Lund, Division of Infection Medicine, Lund University, Lund, Sweden

Full list of author information is available at the end of the article
}

[2]. Moreover, the protein also possesses antimicrobial activity against gram-positive and gram-negative bacteria, mycobacteria and fungi [3-6], although the mechanisms behind its antimicrobial properties are not fully understood.

Chronic obstructive pulmonary disease (COPD) and cystic fibrosis (CF) are two conditions affecting the lungs. Although the pathophysiology differs between the two diseases, they have several clinical manifestations in common. COPD is typically caused by long-term exposure to cigarette smoke, resulting in deterioration of lung function. In severe cases, these patients usually require long-term 
oxygen treatment due to hypoxaemia [7]. CF, on the other hand, is caused by a defect in the CF transmembrane conductance regulator gene, resulting in impaired chloride transport and excess mucus production [8]. Inflammation and infection are hallmarks of both diseases, and also major causes of the deterioration of respiratory function. The pathogenesis of both conditions is believed to involve a protease-antiprotease imbalance, where the protease activity from inflammatory cells is not adequately counter-acted by anti-proteases $[9,10]$. Moreover, bacteria often colonize the lungs of these patients, and they frequently suffer from airway infections and exacerbation that have profound effects on morbidity and mortality [11-14]. Given that SLPI has both antimicrobial and antiprotease properties, regulation of the protein may have important implications for disease progression.

Transforming growth factor $\beta 1$ (TGF- $\beta 1$ ) is a pleiotropic, multifunctional growth factor with fibrogenic and immunomodulatory properties. The protein has been implicated as an important regulator in the pathogenesis of inflammatory pulmonary conditions such as COPD, and an increase in TGF- $\beta 1$ signalling has been seen in the lung in several studies on COPD (for a review, see [15]). Interestingly, TGF- $\beta 1$ has also been shown to regulate SLPI expression [16].

In healthy tissues, the oxygen tension is normally between 2.5 and $9 \%$, corresponding to $20-70 \mathrm{mmHg}$ oxygen. During infections and inflammatory processes, oxygen is consumed by inflammatory cells at the infectious site, resulting in a hypoxic microenvironment with oxygen levels below $1 \%(<8 \mathrm{mmHg})[17,18]$. COPD and CF patients have hypoxic areas in their lungs due to mucus plugs in the bronchi, chronic inflammation and tissue remodelling, resulting in shunting of blood from poorly to well ventilated areas. It is known that hypoxia increases the inflammatory function of inflammatory cells [18], but very little is known about the effects of hypoxia on the production of anti-proteases such as SLPI in the airway epithelium.

The present study was performed to investigate the impact of hypoxia on the secretion of SLPI by the respiratory epithelium. The results show that SLPI is down-regulated in bronchial epithelial cells in response to hypoxia, and that this is mediated via a TGF- $\beta 1$ dependent mechanism.

\section{Methods}

\section{Chemicals and reagents}

Recombinant human TGF- $\beta 1$ was purchased from Millipore (Darmstadt, Germany). Neutralizing monoclonal antibody against TGF- $\beta 1$ and corresponding isotype IgG were obtained from R\&D Systems (Minneapolis, MN, USA).

\section{Cells and culturing conditions}

Primary human bronchial epithelial cells from nonsmokers (3H Biomedical, Uppsala, Sweden) were grown in BEGM medium supplemented with BEGM bullet kit (Lonza, Basel, Switzerland) in poly-L-lysine-coated flasks (Sigma, St. Louis, MO, USA). The cells were seeded in 24well plates (Sigma) coated with $\mathrm{PurCol}^{\circ}$ (Advanced BioMatrix, San Diego, CA, USA) (1:100 v/v in $\left.\mathrm{H}_{2} \mathrm{O}\right)$. Cells were grown until they were confluent and then incubated for $72 \mathrm{~h}$ with or without different stimuli under normoxia $\left(21 \% \mathrm{O}_{2}, 5 \% \mathrm{CO}_{2}\right)$ or hypoxia $\left(1 \% \mathrm{O}_{2}, 5 \% \mathrm{CO}_{2}\right)$. Hypoxic incubation was performed in a C-Chamber (BioSpherix, Lacona, NY, USA). After $48 \mathrm{~h}$ of incubation, the medium was replaced with fresh medium including stimuli. This medium had been pre-incubated in the cell incubator under hypoxic or normoxic conditions. At the end of the incubation period, the cell medium was collected and stored at $-80^{\circ} \mathrm{C}$ until analysis.

For the growth of air liquid interface (ALI) cell cultures, Transwell $^{\odot}$ inserts in a 12 -well plate were coated with $300 \mu \mathrm{l} \mathrm{PurCol}\left(1: 100 \mathrm{v} / \mathrm{v}\right.$ in $\left.\mathrm{H}_{2} \mathrm{O}\right)$ for $20 \mathrm{~min}$. Primary human bronchial epithelial cells were thereafter seeded onto the inserts and maintained in BEGM medium in subimmersed cultures. When confluence was reached, the apical medium was removed and the baso-lateral medium was replaced by ALI medium, consisting of one part BEGM medium supplemented with BEGM bullet kit and $3 \mathrm{mg} / \mathrm{ml}$ BSA (Sigma), and one part D-MEM (Invitrogen, Walthem, MA, USA) supplemented with $1 \mathrm{mM}$ sodium pyruvate MEM, 2 mM L-glutamine and non-essential amino acids (all from Invitrogen). The cell medium was thereafter changed at least 5 times/week. After 3-4 weeks in ALI culture, the cells were incubated at $21 \%$ or $1 \% \mathrm{O}_{2}$ as above. Hypoxic incubation of the ALI cultures was performed with a glove box, InvivO $\mathrm{O}_{2}$ Hypoxia 400 workstation (Ruskinn Technology Ltd, Bridgend, UK), to allow work under hypoxic conditions. After $48 \mathrm{~h}$ of incubation, the baso-lateral medium was changed and the apical surfaces were rinsed with PBS to remove excess mucus and pre-formed peptides. Incubation was terminated after $72 \mathrm{~h}$ by rinsing the apical surfaces with $100 \mu \mathrm{l} 10 \mathrm{mM}$ Tris buffer with $5 \mathrm{mM}$ glucose. The rinsing fluids were stored at $-80^{\circ} \mathrm{C}$ until analysis.

\section{SLPI detection}

SLPI was detected in cell medium supernatants and rinsing fluids with ELISA (R\&D Systems) according to the manufacturer's protocol. As the volumes of the medium and rinsing fluids were known, the total amounts of SLPI released apically and baso-laterally could be compared.

\section{RNA isolation and real-time PCR}

Total RNA was isolated from primary human bronchial epithelial cells using the acid guanidinium phenol 
chloroform method and the RNeasy Mini Kit supplied by Qiagen (Hilden, Germany). The optical density ratio (OD $260 \mathrm{~nm} / \mathrm{OD} 280 \mathrm{~nm}$ ) of RNA was always greater than 1.95. Reverse transcription was performed according to the manufacturer's instructions on $1 \mu \mathrm{g}$ total RNA using an iScript ${ }^{\mathrm{TM}}{ }^{\mathrm{cDNA}}$ Synthesis Kit (Bio-Rad, Hercules, CA, USA). RT-PCR was then used to quantify TGF- $\beta 1$ and SLPI mRNA expression with primer pairs from OriGene Technologies (Rockville, MD, USA). Data were normalized to succinate dehydrogenase complex subunit A. This was chosen as internal standard based on analyses of the expression of a panel of 7 genes commonly used for normalization under hypoxic conditions (data not shown). Expression was analysed using the iTaq $^{\mathrm{Tm}}$ Universal SYBR ${ }^{\oplus}$ Green Supermix (Bio-Rad). Amplification was performed at $55^{\circ} \mathrm{C}$ for 40 cycles in an iCycler Thermal Cycler (BioRad) and data were analysed using iCycler iQ Optical System Software (Bio-Rad).

\section{Neutrophil elastase activity assay}

Neutrophil elastase activity was analysed with the chromogenic substrate N-methoxysuccinyl-Ala-Ala-Pro-Val pnitroanilide (Sigma). The baso-lateral cell medium from ALI-cultures was diluted 1:4 in HEPES buffer $(0.1 \mathrm{M}$ HEPES pH $7.5+0.5 \mathrm{M} \mathrm{NaCl}$ ). Fresh cell medium was used as a control. Equal amounts of diluted cell medium and $0.05 \mathrm{U} / \mathrm{ml}$ neutrophil elastase in HEPES buffer $(40 \mu \mathrm{l}$ each) (Sigma, St. Louis, MO, USA) were mixed in a 96well plate. Samples were incubated at room temperature for $20 \mathrm{~min}$. To each well, $100 \mu \mathrm{l}$ of $0.2 \mathrm{mM} \mathrm{N}$-methoxysuccinyl-Ala-Ala-Pro-Val p-nitroanilide in HEPES buffer was added. The plate was incubated at room temperature, and the absorbance was determined at $405 \mathrm{~nm}$ at different time points.

\section{Statistical analysis}

Statistical calculations were performed using Student's $T$-test or one-way ANOVA. Differences were considered statistically significant at $\mathrm{p}<0.05$.

\section{Results}

SLPI expression in bronchial epithelial cells is reduced in response to hypoxia

In order to study the effects of hypoxia on the secretion of SLPI in the airways, primary human bronchial epithelial cells were grown in ALI cultures. Under these conditions, cells differentiate to form a ciliated epithelium with mucus production similar to the in vivo airway epithelium. The differentiated cell cultures were incubated at $21 \%$ or $1 \%$ $\mathrm{O}_{2}$ for $72 \mathrm{~h}$, after which the cell medium was collected, and the apical surfaces were rinsed to collect the periciliary liquid (PCL) including secreted proteins and peptides. Cells grown under hypoxic conditions were adherent and could not be morphologically distinguished from normoxic cells with light microscopy. The SLPI content in medium and rinsing fluids was analysed with ELISA. SLPI was mostly released into the baso-lateral medium (349 \pm $25 \mathrm{ng} / \mathrm{ml})$ compared to the rinsing fluid $(53 \pm 12 \mathrm{ng} / \mathrm{ml})$ (Figure 1). However, if it is assumed that the depth of the PCL was $5 \mu \mathrm{m}$ [19], the apical SLPI levels in the PCL would have been much higher at approximately $8 \mu \mathrm{g} / \mathrm{ml}$, which is in good agreement with in vivo data [20]. SLPI concentrations were significantly reduced in both compartments in response to hypoxia (Figure 1).

We next investigated the effects of hypoxia on SLPI expression in non-differentiated primary bronchial epithelial cells grown in sub-immersed cultures. These cells were incubated at $21 \%$ or $1 \% \mathrm{O}_{2}$, and SLPI concentrations in the cell medium were analysed after $72 \mathrm{~h}$ of incubation. SLPI levels were found to be reduced in cells grown under hypoxic conditions (Figure 2A), in line with the data from ALIcultures. Cells were also harvested and analysed for mRNA expression using RT-PCR. The results showed that SLPI mRNA is down-regulated in response to hypoxia (Figure 2B), indicating that SLPI expression in a hypoxic

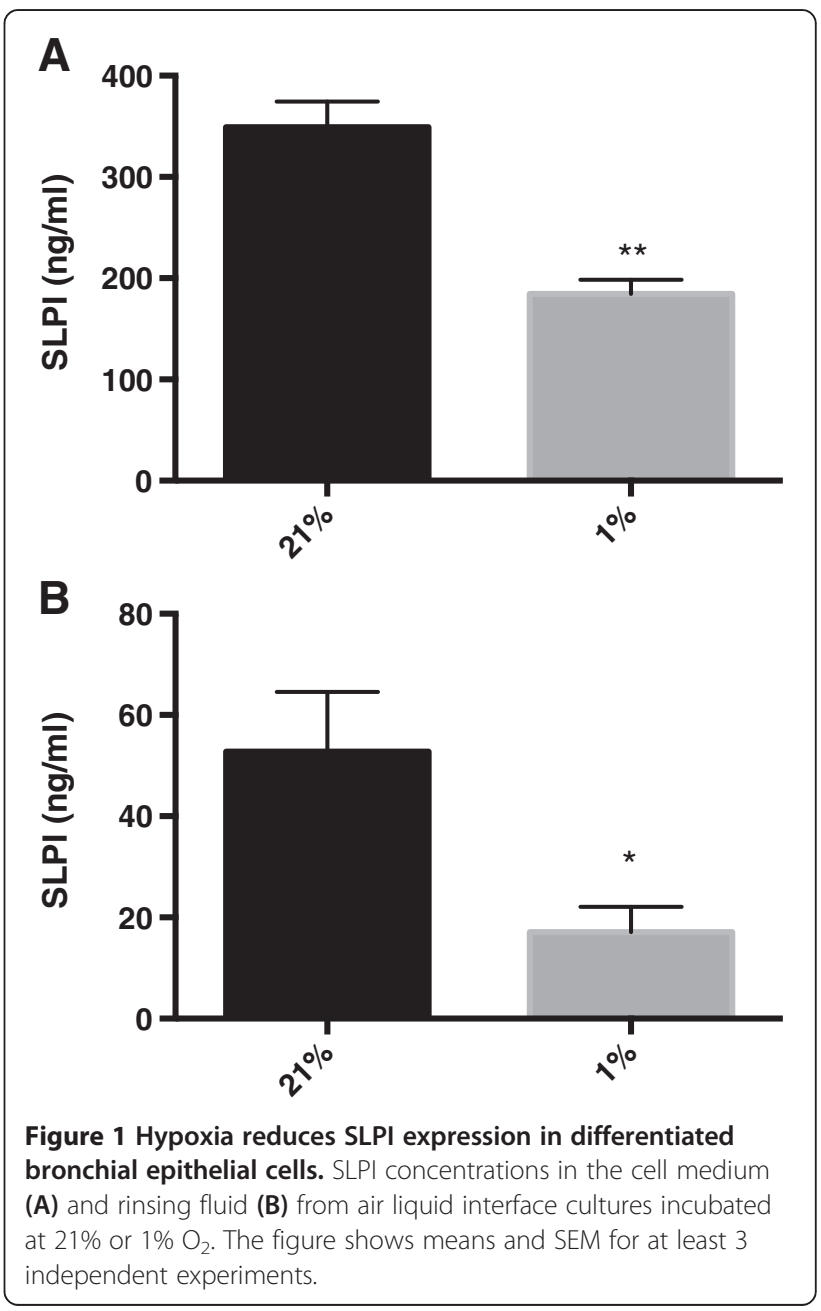




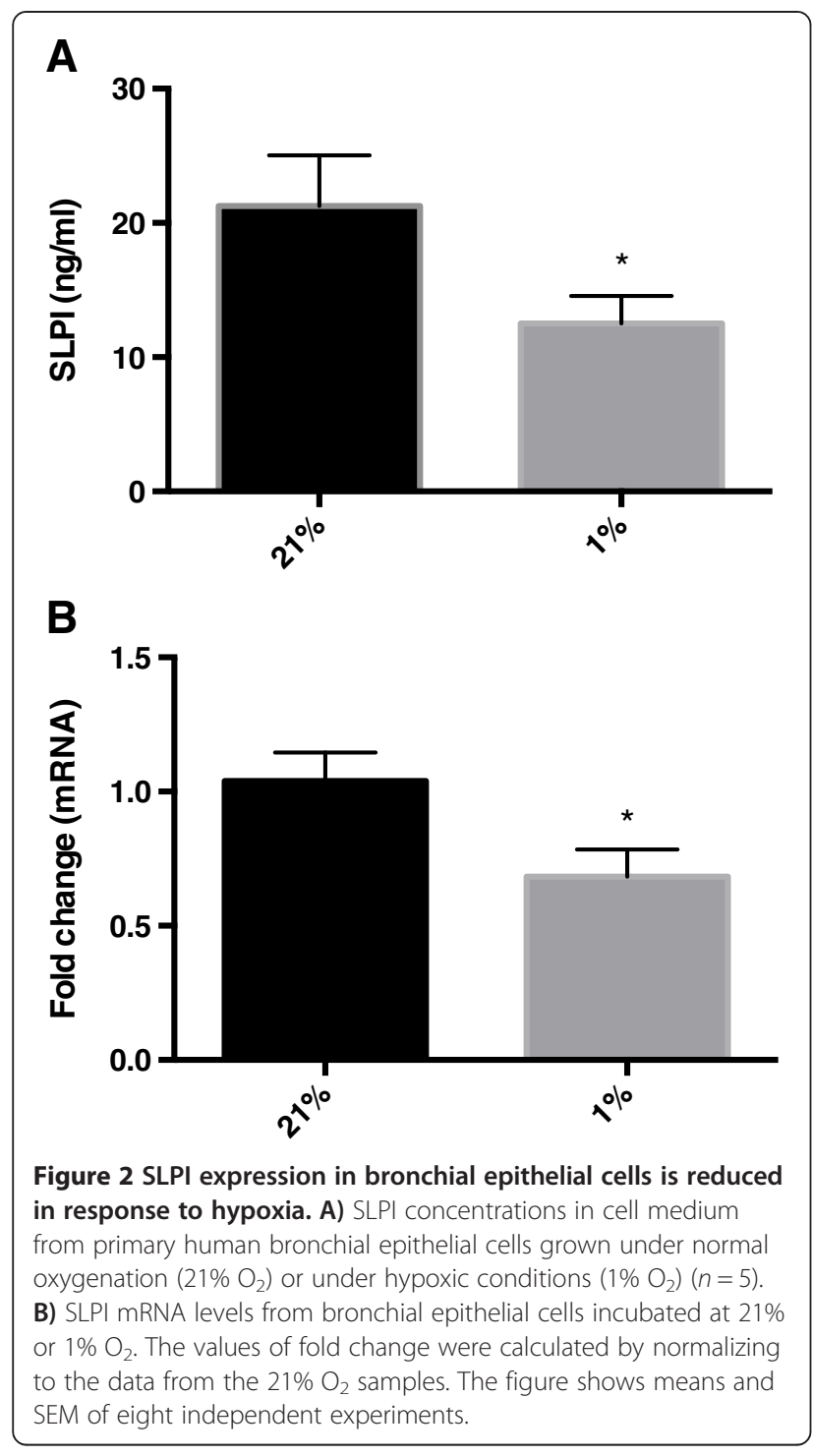

environment is controlled at the transcriptional level, and is not a consequence of an overall reduction in metabolism.

Since the response to hypoxia was similar in both cell culturing systems, we continued to work with nondifferentiated cells to facilitate the studies of underlying mechanisms.

\section{Hypoxia regulates SLPI expression via TGF- $\beta 1$ signaling}

TGF- $\beta 1$ is a growth factor that has been shown to downregulate SLPI [16]. To confirm that SLPI can be regulated by TGF- $\beta 1$ in the airways, bronchial epithelial cells were stimulated for $72 \mathrm{~h}$ with different concentrations of TGF$\beta 1$. SLPI concentrations in the cell medium were thereafter detected with ELISA. SLPI expression decreased with increasing TGF- $\beta 1$ concentrations (Figure $3 \mathrm{~A}$ ), and the down-regulation of SLPI expression was more pronounced over time (Figure 3B).

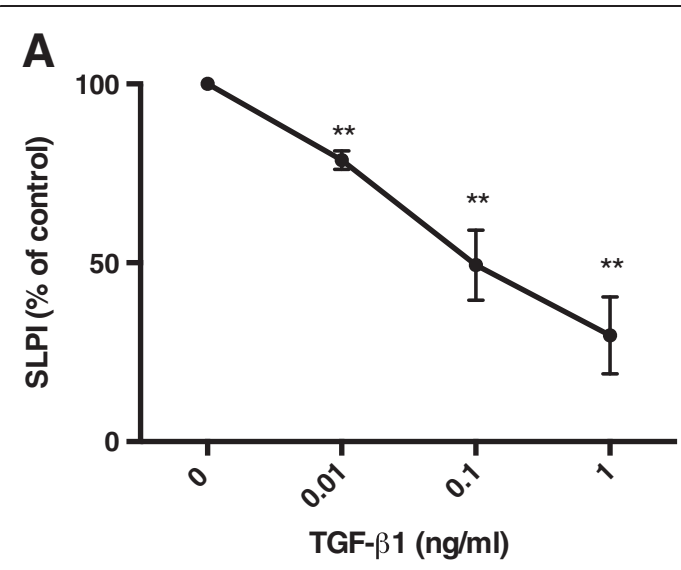

B

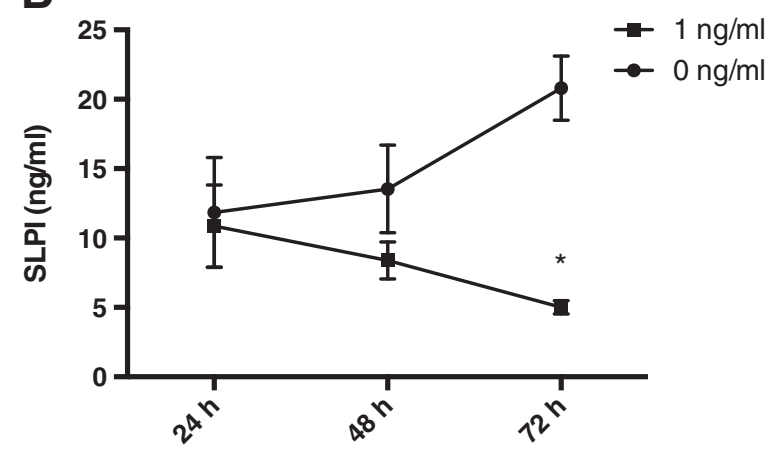

Figure 3 SLPI expression is down regulated by TGF- $\beta 1$. SLPI concentrations in the cell medium from human bronchial epithelial cells stimulated with TGF- $\beta 1$ (A), or in the absence or presence of $1 \mathrm{ng} / \mathrm{ml}$ TGF- $\beta 1$ (B). The figure shows means and SEM of at least three independent experiments.

In order to analyse the effect of hypoxia on TGF- $\beta 1$ expression, RNA was isolated from cells grown in $21 \%$ and $1 \%$ oxygen, and the mRNA expression of TGF- $\beta 1$ and SLPI was subsequently quantified using RT-PCR. TGF- $\beta 1$ mRNA was significantly up-regulated in response to hypoxia (Figure $4 \mathrm{~A}$ ). Cells were then incubated in $21 \%$ or $1 \%$ $\mathrm{O}_{2}$, in the presence of a neutralizing antibody against TGF- $\beta 1$. An isotype control antibody was used in parallel. Compared to the control antibody, SLPI expression in hypoxic cells was increased in response to anti-TGF- $\beta 1$ (Figure 4B). Taken together, these results suggest that hypoxia down-regulates SLPI expression via up-regulation of TGF- $\beta 1$ in bronchial epithelial cells.

\section{Medium from hypoxic cells is less potent in inhibiting neutrophil elastase activity}

To investigate whether hypoxia affects the anti-protease property of the airway epithelium, baso-lateral cell medium from ALI cells stimulated with $21 \%$ or $1 \%$ oxygen was incubated with neutrophil elastase. Elastase activity was thereafter measured using a chromogenic assay. The results show a small but statistically significant difference between normoxic 


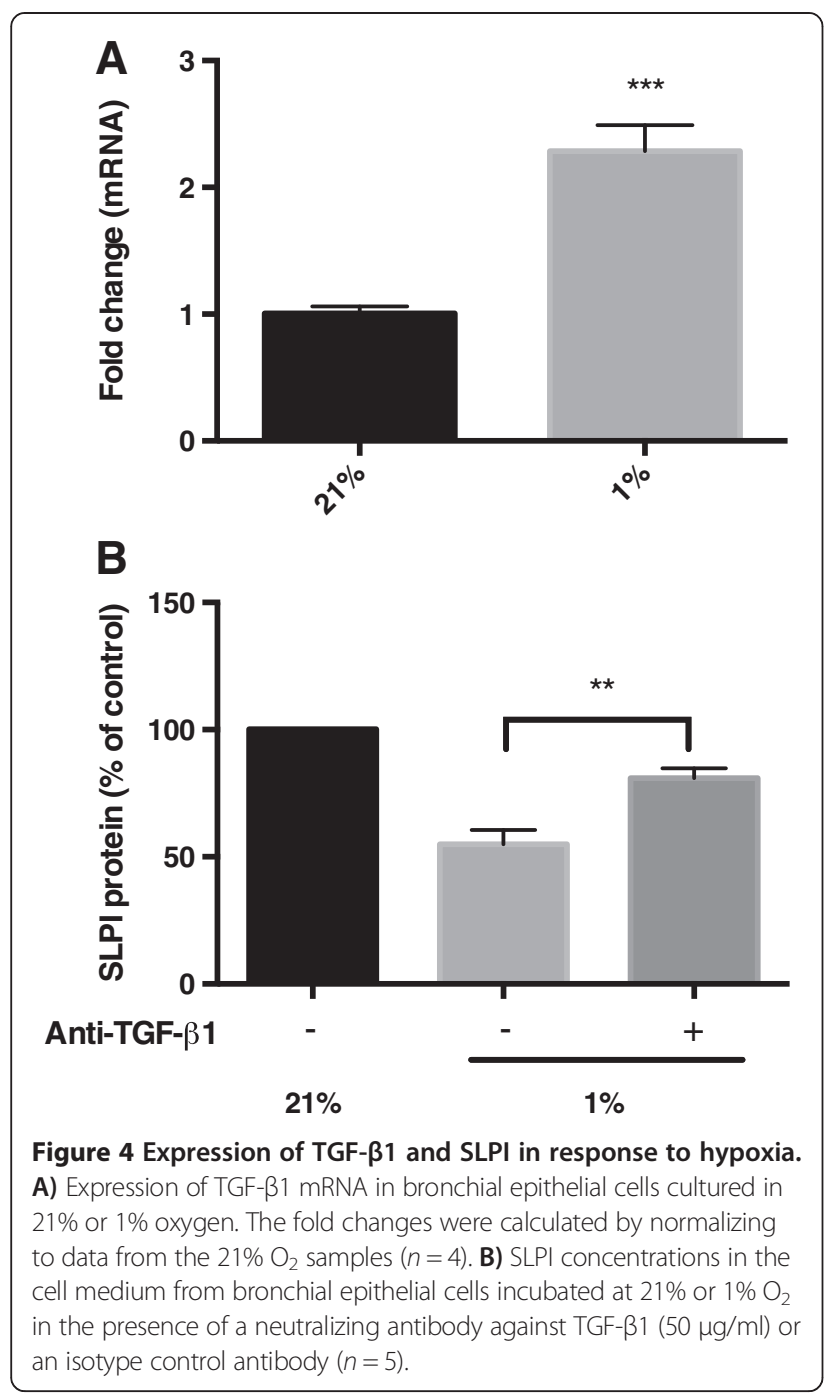

and hypoxic cell medium, where medium from normoxic cells inhibited elastase activity more efficiently (Additional file 1: Figure S1). These results indicate that hypoxia reduces the anti-protease potential of the airway epithelium.

\section{Discussion}

We have demonstrated a mechanism whereby SLPI is down-regulated in the airway epithelium in response to hypoxia (Figure 5). Under normal conditions, SLPI is constitutively expressed in epithelial cells. When oxygen is limited, hypoxia promotes up-regulation of TGF- $\beta 1$, which in turn down-regulates SLPI.

When tissues are exposed to hypoxia, cells respond by upregulating a number of genes, mainly through the hypoxiainducible factor (HIF) pathways. HIFs are heterodimeric transcription factors that are rapidly degraded under conditions of normal oxygenation, but are stabilized and accumulate during hypoxia [21]. It has been reported that HIF- $1 \alpha$ is up-regulated in the airways of patients with COPD and chronic bronchitis [22,23]. Although HIF-1 $\alpha$ has been shown to regulate the TGF- $\beta 1$ gene in mesenchymal stem cells [24], further studies are needed to investigate whether TGF- $\beta 1$ and SLPI in the airways are regulated via HIF- $1 \alpha$ or other hypoxia-driven pathways under hypoxic conditions. However, the increase in HIF- $1 \alpha$ in the airways of COPD patients indicates that they have hypoxic regions in their lungs. Studies using direct oxygen measurements in the lungs of CF patients have demonstrated a hypoxic environment in the airway mucus, with mean oxygen levels as low as $2.5 \mathrm{mmHg}$ [25]. SLPI concentrations in the airways of COPD and CF patients are reduced during bacterial exacerbation, and it has been postulated that the mechanism behind this observation involves proteolytic cleavage of the protein by neutrophil elastase [26-29]. Here, we propose a complementary mechanism whereby aggravated hypoxia

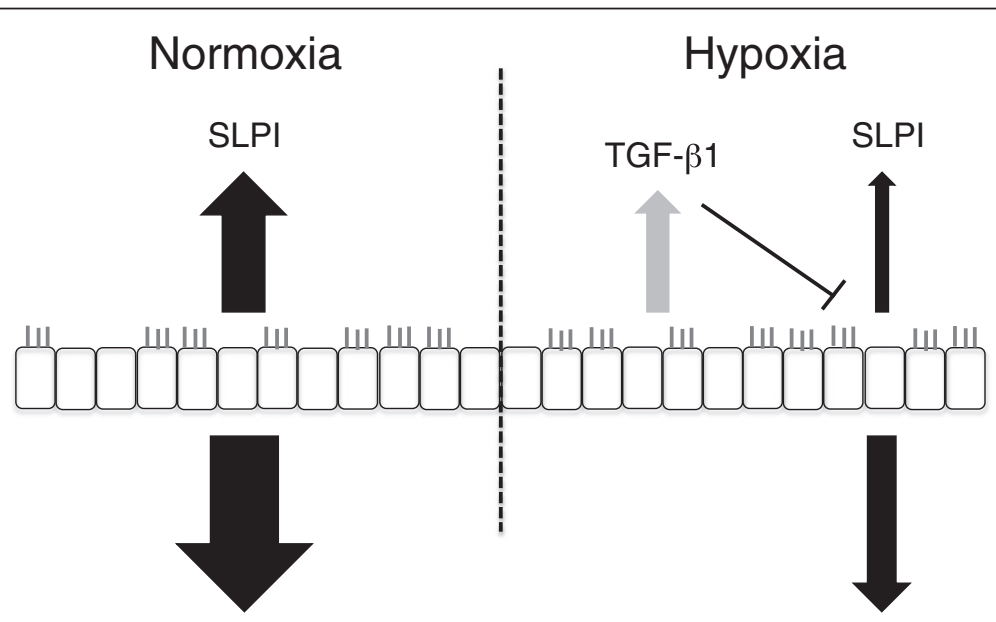

Figure 5 Schematic model of hypoxia-driven SLPI expression. During normal oxygenation, the bronchial epithelium constitutively secretes SLPI, both apically and baso-laterally. When the oxygen concentrations decrease, the epithelium increases its expression of TGF- $\beta 1$, which in turn down-regulates SLPI production. 
during infection contributes to the reduction in SLPI concentration. Interestingly, it has also been reported that down-regulation of SLPI in COPD involves TGF- $\beta 1$ signalling [30], which supports our model.

Conflicting data have been reported regarding the effects of hypoxia on TGF- $\beta 1$ secretion. Boussat and co-workers found no change in TGF- $\beta 1$ protein levels in the cell medium from pulmonary epithelial cells grown under hypoxic conditions [31], whereas others have reported an increase in TGF- $\beta 1$ protein in response to hypoxia [24]. Our data show that neutralization of TGF- $\beta 1$ with an antibody increases SLPI levels in hypoxic cells, suggesting that TGF$\beta 1$ concentrations are elevated under hypoxic conditions. Interestingly, Ambalavanan and co-workers showed that mice exposed to hypoxia exhibit an increased level of active TGF- $\beta 1$ in their lungs, whereas total TGF- $\beta 1$ concentrations were unchanged compared with controls [32]. This observation may explain the conflicting results on TGF- $\beta 1$ levels in response to hypoxia.

SLPI was originally identified as a physiologically important inhibitor of neutrophil elastase and other proteases. Dysregulation of SLPI levels in the lungs of COPD and CF patients would therefore render them more vulnerable to damage caused by the inflammatory response. It is now known that the protein also has antimicrobial and immunomodulatory functions. SLPI has been shown to be effective against a number of gram-positive and gram-negative bacteria, including species common in the CF and COPD respiratory tract, such as Pseudomonas aeruginosa and Staphylococcus aureus [3,33]. Furthermore, SLPI can inhibit the inflammatory response by binding to lipopolysaccharide, thereby preventing macrophage activation [34]. This has been demonstrated in vivo, where SLPI-deficient mice challenged with lipopolysaccharide showed higher mortality and higher IL-6 expression than wildtype mice [35]. Moreover, clinical studies in which CF patients were given aerosolized recombinant SLPI have demonstrated that SLPI not only neutralizes neutrophil elastase activity, but also has an immunoregulatory effect, reducing IL-8 and neutrophil levels in the epithelial lining fluid [36,37]. This multifunctional role of SLPI makes it interesting from a therapeutic point of view, as altering this system could potentially reduce overexaggerated proteolytic activity in inflammatory lung diseases such as COPD and CF, modulate the inflammatory response, and protect these patients from bacterial infections [38].

A limitation of the present study is that only epithelial cells were studied. Fibroblasts, endothelial cells and inflammatory cells were not studied, and their contributions to SLPI regulation in an in vivo setting are therefore unknown. Moreover, the experiments were carried out under noninflammatory conditions. Further studies are thus needed to evaluate how hypoxia effects SLPI expression in the presence of normal airway microbiota, airway pathogens or other inflammatory stimuli.

\section{Conclusion}

In conclusion, the present study demonstrates that SLPI is down-regulated in the bronchial epithelium during hypoxia. These findings may help explain the pathogenesis of inflammatory lung diseases, and provide a potential target for the treatment and prevention of exacerbation in these patients.

\section{Additional file}

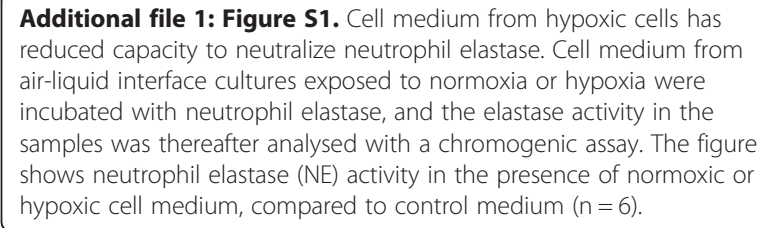

Additional file 1: Figure S1. Cell medium from hypoxic cells has reduced capacity to neutralize neutrophil elastase. Cell medium from air-liquid interface cultures exposed to normoxia or hypoxia were incubated with neutrophil elastase, and the elastase activity in the samples was thereafter analysed with a chromogenic assay. The figure shows neutrophil elastase (NE) activity in the presence of normoxic or hypoxic cell medium, compared to control medium $(n=6)$.

\section{Abbreviations}

SLPI: Secretory leucocyte protease inhibitor; COPD: Chronic obstructive pulmonary disease; CF: Cystic fibrosis; TGF- $\beta 1$ : Transforming growth factor B1; ALI: Air liquid interface; PCL: Periciliary liquid; HIF-1a: Hypoxia-inducible factor-1a.

\section{Competing interests}

The authors declare that they have no competing interests.

\section{Authors' contributions}

$L P$ and $A E$ conceived of the study, participated in the design and coordination of the study, and drafted the manuscript. LP, AJ, MG and MM carried out the experiments. All authors read and approved the final manuscript.

\section{Acknowledgements}

The authors wish to thank Pia Andersson and Gisela Håkansson for excellent technical assistance. This study was supported by grants from the Swedish Heart and Lung Foundation, the Swedish Government Funds for Clinical Research (ALF), and the Magnus Bergvall, Tore Nilson, and Skåne University Hospital in Lund foundations.

\section{Author details}

${ }^{1}$ Department of Clinical Sciences Lund, Division of Infection Medicine, Lund University, Lund, Sweden. 'Lund University Cancer Center at Medicon Village, Translational Cancer Research, Department of Laboratory Medicine Lund, Lund University, Lund, Sweden. ${ }^{3}$ Department of Experimental Medical Sciences, Airway Inflammation and Immunology, Lund University, Lund, Sweden. ${ }^{4}$ Department of Clinical Sciences Lund, Respiratory Medicine and Allergology, Lund University, Lund, Sweden.

Received: 14 October 2014 Accepted: 20 February 2015

Published online: 07 March 2015

\section{References}

1. Williams SE, Brown TI, Roghanian A, Sallenave JM. SLPI and elafin: one glove, many fingers. Clin Sci (Lond). 2006;110:21-35.

2. Thompson RC, Ohlsson K. Isolation, properties, and complete amino acid sequence of human secretory leukocyte protease inhibitor, a potent inhibitor of leukocyte elastase. Proc Natl Acad Sci U S A. 1986;83:6692-6.

3. Hiemstra PS, Maassen RJ, Stolk J, Heinzel-Wieland R, Steffens GJ, Dijkman JH. Antibacterial activity of antileukoprotease. Infect Immun. 1996;64:4520-4.

4. Tomee JF, Hiemstra PS, Heinzel-Wieland R, Kauffman HF. Antileukoprotease: an endogenous protein in the innate mucosal defense against fungi. J Infect Dis. 1997;176:740-7.

5. Gomez SA, Arguelles CL, Guerrieri D, Tateosian NL, Amiano NO, Slimovich R, et al. Secretory leukocyte protease inhibitor: a secreted pattern recognition receptor for mycobacteria. Am J Respir Crit Care Med. 2009;179:247-53. 
6. Cooper MD, Roberts MH, Barauskas OL, Jarvis GA. Secretory leukocyte protease inhibitor binds to Neisseria gonorrhoeae outer membrane opacity protein and is bactericidal. Am J Reprod Immunol. 2012;68:116-27.

7. Calverley PM. COPD: what is the unmet need? Br J Pharmacol. 2008;155:487-93.

8. Rowe SM, Miller S, Sorscher EJ. Cystic fibrosis. N Engl J Med. 2005:352:1992-2001.

9. Fischer BM, Pavlisko E, Voynow JA. Pathogenic triad in COPD: oxidative stress, protease-antiprotease imbalance, and inflammation. Int J Chron Obstruct Pulmon Dis. 2011;6:413-21.

10. Birrer P, McElvaney NG, Rudeberg A, Sommer CW, Liechti-Gallati S, Kraemer $R$, et al. Protease-antiprotease imbalance in the lungs of children with cystic fibrosis. Am J Respir Crit Care Med. 1994;150:207-13.

11. Bandi V, Apicella MA, Mason E, Murphy TF, Siddiqi A, Atmar RL, et al. Nontypeable Haemophilus influenzae in the lower respiratory tract of patients with chronic bronchitis. Am J Respir Crit Care Med. 2001;164:2114-9.

12. Rosell A, Monso E, Soler N, Torres F, Angrill J, Riise G, et al. Microbiologic determinants of exacerbation in chronic obstructive pulmonary disease. Arch Intern Med. 2005;165:891-7.

13. Sethi S, Murphy TF. Infection in the pathogenesis and course of chronic obstructive pulmonary disease. N Engl J Med. 2008;359:2355-65.

14. Zemanick ET, Sagel SD, Harris JK. The airway microbiome in cystic fibrosis and implications for treatment. Curr Opin Pediatr. 2011;23:319-24.

15. Yang YC, Zhang N, Van Crombruggen K, Hu GH, Hong SL, Bachert C. Transforming growth factor-beta1 in inflammatory airway disease: a key for understanding inflammation and remodeling. Allergy. 2012:67:1193-202.

16. Jaumann F, Elssner A, Mazur G, Dobmann S, Vogelmeier C. Transforming growth factor-beta1 is a potent inhibitor of secretory leukoprotease inhibitor expression in a bronchial epithelial cell line. Munich Lung Transplant Group. Eur Respir J. 2000;15:1052-7.

17. Taylor CT. Interdependent roles for hypoxia inducible factor and nuclear factor-kappaB in hypoxic inflammation. J Physiol. 2008;586:4055-9.

18. Nizet $\mathrm{V}$, Johnson RS. Interdependence of hypoxic and innate immune responses. Nat Rev Immunol. 2009;9:609-17.

19. Chen JH, Stoltz DA, Karp PH, Ernst SE, Pezzulo AA, Moninger TO, et al. Loss of anion transport without increased sodium absorption characterizes newborn porcine cystic fibrosis airway epithelia. Cell. 2010;143:911-23.

20. Travis SM, Singh PK, Welsh MJ. Antimicrobial peptides and proteins in the innate defense of the airway surface. Curr Opin Immunol. 2001;13:89-95.

21. Metzen E, Ratcliffe PJ. HIF hydroxylation and cellular oxygen sensing. Biol Chem. 2004:385:223-30.

22. Polosukhin W, Cates JM, Lawson WE, Milstone AP, Matafonov AG, Massion PP et al. Hypoxia-inducible factor-1 signalling promotes goblet cell hyperplasia in airway epithelium. J Pathol. 2011;224:203-11.

23. Lee $\mathrm{SH}$, Lee $\mathrm{SH}$, Kim CH, Yang KS, Lee EJ, Min KH, et al. Increased expression of vascular endothelial growth factor and hypoxia inducible factor-1alpha in lung tissue of patients with chronic bronchitis. Clin Biochem. 2014:47:552-9.

24. Hung SP, Yang MH, Tseng KF, Lee OK. Hypoxia-induced secretion of TGF-beta1 in mesenchymal stem cell promotes breast cancer cell progression. Cell Transplant. 2013;22:1869-82.

25. Worlitzsch D, Tarran R, Ulrich M, Schwab U, Cekici A, Meyer KC, et al. Effects of reduced mucus oxygen concentration in airway Pseudomonas infections of cystic fibrosis patients. J Clin Invest. 2002;109:317-25.

26. Parameswaran Gl, Sethi S, Murphy TF. Effects of bacterial infection on airway antimicrobial peptides and proteins in COPD. Chest. 2011;140:611-7.

27. Parameswaran Gl, Wrona CT, Murphy TF, Sethi S. Moraxella catarrhalis acquisition, airway inflammation and protease-antiprotease balance in chronic obstructive pulmonary disease. BMC Infect Dis. 2009:9:178.

28. Mallia P, Footitt J, Sotero R, Jepson A, Contoli M, Trujillo-Torralbo MB, et al. Rhinovirus infection induces degradation of antimicrobial peptides and secondary bacterial infection in chronic obstructive pulmonary disease. Am J Respir Crit Care Med. 2012;186:1117-24.

29. Weldon S, McNally P, McElvaney NG, Elborn JS, McAuley DF, Wartelle J, et al. Decreased levels of secretory leucoprotease inhibitor in the Pseudomonas-infected cystic fibrosis lung are due to neutrophil elastase degradation. J Immunol. 2009;183:8148-56.

30. Luo BL, Niu RC, Feng JT, Hu CP, Xie XY, Ma LJ. Downregulation of secretory leukocyte proteinase inhibitor in chronic obstructive lung disease: the role of TGF-beta/Smads signaling pathways. Arch Med Res. 2008;39:388-96.

31. Boussat S, Eddahibi S, Coste A, Fataccioli V, Gouge M, Housset B, et al. Expression and regulation of vascular endothelial growth factor in human pulmonary epithelial cells. Am J Physiol Lung Cell Mol Physiol. 2000;279: L371-8.

32. Ambalavanan N, Nicola T, Hagood J, Bulger A, Serra R, Murphy-Ullrich J, et al. Transforming growth factor-beta signaling mediates hypoxia-induced pulmonary arterial remodeling and inhibition of alveolar development in newborn mouse lung. Am J Physiol Lung Cell Mol Physiol. 2008;295:L86-95.

33. Wiedow O, Harder J, Bartels J, Streit V, Christophers E. Antileukoprotease in human skin: an antibiotic peptide constitutively produced by keratinocytes. Biochem Biophys Res Commun. 1998;248:904-9.

34. Ding A, Thieblemont N, Zhu J, Jin F, Zhang J, Wright S. Secretory leukocyte protease inhibitor interferes with uptake of lipopolysaccharide by macrophages. Infect Immun. 1999;67:4485-9.

35. Nakamura A, Mori Y, Hagiwara K, Suzuki T, Sakakibara T, Kikuchi T, et al. Increased susceptibility to LPS-induced endotoxin shock in secretory leukoprotease inhibitor (SLPI)-deficient mice. J Exp Med. 2003:197:669-74.

36. McElvaney NG, Nakamura H, Birrer P, Hebert CA, Wong WL, Alphonso M, et al. Modulation of airway inflammation in cystic fibrosis. In vivo suppression of interleukin-8 levels on the respiratory epithelial surface by aerosolization of recombinant secretory leukoprotease inhibitor. J Clin Invest. 1992;90:1296-301.

37. McElvaney NG, Doujaiji B, Moan MJ, Burnham MR, Wu MC, Crystal RG. Pharmacokinetics of recombinant secretory leukoprotease inhibitor aerosolized to normals and individuals with cystic fibrosis. Am Rev Respir Dis. 1993;148:1056-60.

38. Zani ML, Tanga A, Saidi A, Serrano H, Dallet-Choisy S, Baranger K, et al. SLP and trappin-2 as therapeutic agents to target airway serine proteases in inflammatory lung diseases: current and future directions. Biochem Soc Trans. 2011:39:1441-6.

\section{Submit your next manuscript to BioMed Central and take full advantage of:}

- Convenient online submission

- Thorough peer review

- No space constraints or color figure charges

- Immediate publication on acceptance

- Inclusion in PubMed, CAS, Scopus and Google Scholar

- Research which is freely available for redistribution 